\title{
Autoimmune/autoinflammatory syndrome induced by adjuvants (ASIA) after a silicone injection
}

\author{
Victor G Becerra-Gonzales (D) ,' Amarilys Alarcon-Calderon, ${ }^{1}$ Garly Saint Croix, ${ }^{1}$ \\ David De La Zerda
}

${ }^{1}$ Internal Medicine, Jackson Memorial Hospital, Miami, Florida, USA

${ }^{2}$ Pulmonary and Critical Care Medicine, Jackson Memorial Hospital, Miami, Florida, USA

\section{Correspondence to}

Dr Victor G Becerra-Gonzales; victor.becerragonza@jhsmiami. org

Accepted 25 March 2020

\section{DESCRIPTION}

Autoimmune/autoinflammatory syndrome induced by adjuvants (ASIA) corresponds to a spectrum of immune-mediated diseases triggered by chronic exposure to adjuvants which are substances meant to enhance antigen-specific immune response. ${ }^{1}$ Silicone implants have been generally considered relatively inert materials; however, they could generate systemic autoimmune reactions in genetically susceptible individuals leading to ASIA. We describe a case of severe ASIA after cosmetic silicone injections. A 49-year-old woman presented to the emergency department with 3 weeks of persistent fever, chills, dysphagia and worsening dyspnoea. She had been previously healthy and had no sick contacts. One month prior to her presenting symptoms, silicone was injected to her breast and gluteus for an augmentation procedure. On physical examination, she had tenderness to palpation in the thyroid area, multiple neck and axillary lymphadenopathies and few non-tender small nodules in the abdominal wall. CT chest and abdomen showed innumerable well circumscribed and calcified lesions involving the chest wall, mediastinum, pericardium, bilateral hilar regions extending to the pleural space and thickened oesophagus (figures 1 and 2). Biopsy of the skin nodule at the site of injection showed silicon granuloma that confirmed the diagnosis of ASIA. She was treated with steroids with resolution of fever and chills; however, dysphagia and dyspnea only improved partially. Over the course of 12 years, she had multiple hospital admission due to worsening dyspnea or dysphagia. Repeating

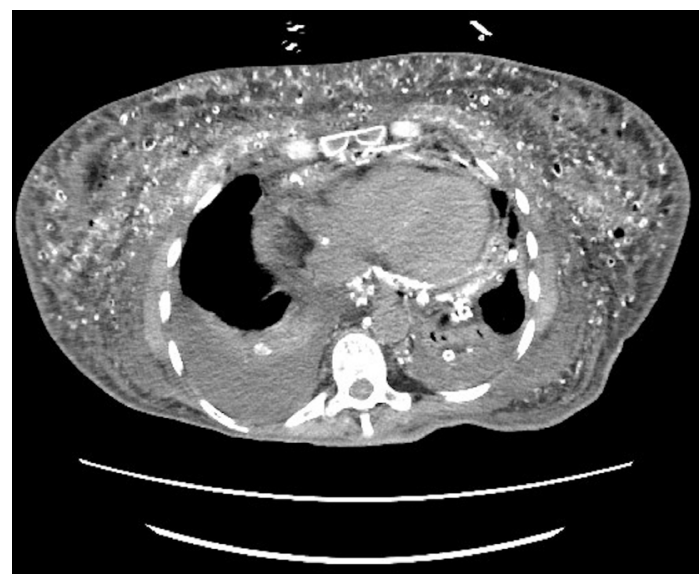

Figure 1 Transversal view of CT chest showing circumscribed and calcified lesions involving the chest wall, mediastinum, pericardium and bilateral hilar region.

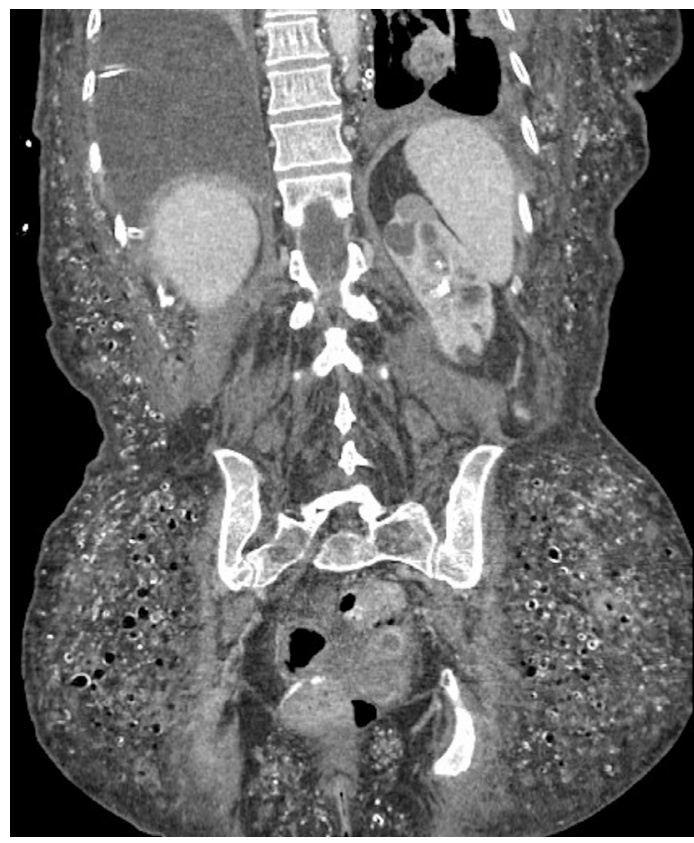

Figure 2 Coronal view of the CT chest/abdomen showing diffuse involvement of multiple circumscribed and calcified lesions in subcutaneous tissue.

imaging depicted extensive fibrosis involving the pericardium, pleural and gastrointestinal tract. She had esophageal structures requiring multiple dilations and percutaneous feeding tube. Unfortunately, fibrosis was not reversible, and she developed chronic respiratory failure. This diagnosis corresponds to a dysregulation of either the innate or adaptative immune reaction in genetically susceptible individuals triggered by the exposure of an adjuvant (a substance that enhances the immune response to antigens). Some adjuvants have been linked to a severe diffuse inflammatory reaction

Learning points

- Silicone may act as an adjuvant substance that can trigger a dysregulated systemic autoinflammatory or autoimmune reaction with multiorgan involvement in susceptible individuals.

- Autoimmune/autoinflammatory syndrome induced by adjuvants is a rare condition and it has been associated with exposure to other inert material (paraffin, acrylamides, hyaluronic acid or methacrylate). 
mediated by innate immune pattern recognition receptor activation such as paraffin, silicone, acrylamides, hyaluronic acid or methacrylate. Silicone was previously considered an inert material, but multiple cases of autoimmune diseases have been reported following silicone implants, mainly undifferentiated connective tissue disorder, but also systemic lupus erythematosus (SLE), rheumatoid arthritis (RA), vasculitis and systemic sclerosis. It has been proposed that there is an increase of profibrotic cytokines, immune dysregulation and antisilicone and anticollagen antibodies. ${ }^{2}$ Thus far, reported cases have had poor prognosis and outcomes. Currently, therapeutic options are limited. Removal of the offending agent can be helpful in some patients.

Twitter Victor G Becerra-Gonzales @Becerra_MD

Contributors VGB-G, AA-C, GSC and DDLZ conceived the presented idea and contributed in planning, conducting, acquisition of clinical information and interpretation of the case report. VGB-G and AA-C performed the literature review.
VGB-G took the lead in writing the manuscript. All authors provided critical feedback and approved the manuscript for publication.

Funding The authors have not declared a specific grant for this research from any funding agency in the public, commercial or not-for-profit sectors.

Competing interests None declared.

Patient consent for publication Obtained.

Provenance and peer review Not commissioned; externally peer reviewed.

\section{ORCID iD}

Victor G Becerra-Gonzales http://orcid.org/0000-0001-5092-2773

\section{REFERENCES}

1 Watad A, Bragazzi NL, McGonagle D, et al. Autoimmune/inflammatory syndrome induced by adjuvants (ASIA) demonstrates distinct autoimmune and autoinflammatory disease associations according to the adjuvant subtype: insights from an analysis of 500 cases. Clin Immunol 2019:203:1-8.

2 Perricone $C$, Colafrancesco S, Mazor RD, et al. Autoimmune/inflammatory syndrome induced by adjuvants (ASIA) 2013: unveiling the pathogenic, clinical and diagnostic aspects. J Autoimmun 2013;47:1-16

Copyright 2020 BMJ Publishing Group. All rights reserved. For permission to reuse any of this content visit

https://www.bmj.com/company/products-services/rights-and-licensing/permissions/

BMJ Case Report Fellows may re-use this article for personal use and teaching without any further permission.

Become a Fellow of BMJ Case Reports today and you can:

- Submit as many cases as you like

- Enjoy fast sympathetic peer review and rapid publication of accepted articles

- Access all the published articles

Re-use any of the published material for personal use and teaching without further permission

\section{Customer Service}

If you have any further queries about your subscription, please contact our customer services team on +44 (0) 2071111105 or via email at support@bmj.com.

Visit casereports.bmj.com for more articles like this and to become a Fellow 